\title{
Acceptance of referral for partners by clients testing positive for human immunodeficiency virus
}

This article was published in the following Dove Press journal:

HIVIAIDS - Research and Palliative Care

21 January 2013

Number of times this article has been viewed

\section{Fetene Netsanet ${ }^{1}$ \\ Ayalew Dessie ${ }^{2}$}

IIMA World Health SuddHealth Multi Donor Trust Fund-Basic Package of Health Services Project, Juba, South Sudan; ${ }^{2}$ United States Agency for International Development, Private Health Sector Program, Abt Associates Inc, Addis Ababa, Ethiopia
Background: Human immunodeficiency virus (HIV)-positive individuals who do not disclose their HIV status to their partners are more likely to present late for HIV and acquired immune deficiency syndrome (AIDS) care than those who have disclosed their HIV status to their partners. A major area of challenge with regards to HIV counseling for clients is disclosure of their HIV status to their partners. The main methods of partner notification are patient referral, provider referral, contract referral, and outreach assistance. The emphasis on a plausible and comprehensive partner referral strategy for widespread positive case detection in resource-limited countries needs to be thought out and developed.

Methods: A qualitative study was conducted among newly HIV-positive clients to identify partners for notification and acceptance of referral by their partners. Health service providers working in HIV testing and counseling clinics were also provided with semistructured questionnaires in order to assess their view towards partner notification strategies for clients testing positive for HIV.

Results: Fifteen newly diagnosed HIV-positive clients were counseled to provide referral slips to their partners. All clients agreed and took the referral card. However, only eight were willing and actually provided the card to their partners. Five of the eight partners of clients who tested HIV-positive and who were provided with referral cards responded to the referral and were tested for HIV. Three were positive and two were negative. Nine of 11 counselors did not agree to requesting partner locator information from HIV-positive clients for contractual referral and/or outreach assistance. The findings from the study were categorized by nine themes. A comprehensive and integrated approach of partner notification and a referral framework with active counselor involvement was developed.

Conclusion: Partner notification and referral can be improved by an integrated and comprehensive framework, with active involvement of HIV counselors in the disclosure process.

Keywords: human immunodeficiency virus, partner notification and referral, partner locator information

\section{Introduction}

The increasing emphasis on partner notification in human immunodeficiency virus (HIV) control programs is backed by empirical evidence showing that it is an effective strategy for preventing transmission of HIV to sexual partners and for promoting early diagnosis and prompt treatment of those found to be infected. ${ }^{1} \mathrm{HIV}$-positive individuals who do not disclose their HIV status to their partners are more likely to present later to HIV and acquired immune deficiency syndrome (AIDS) care services than individuals who have disclosed their HIV status to their partners. ${ }^{2}$
Correspondence: Fetene Netsanet PO Box 100374, Kazanchis/Meskel Square, Addis Ababa, Ethiopia Tel +25I 9 I0 I37506 Email netsanetfetene@gmail.com 
A major challenge with regards to HIV counseling and testing is persuading clients to disclose their HIV status after testing. Disclosure is defined literally as the action of making new or secret information known. However, HIV disclosure is defined as a "complex and multifaceted process of making a voluntary or involuntary decision about whom to inform about one's serostatus". ${ }^{3}$ This is particularly challenging when it comes to informing clients' sexual partners, also referred to as "partner notification". ${ }^{4}$

Partner notification is a process whereby the sexual partners of people diagnosed to have a sexually transmitted infection (STI) are informed of their exposure to infection. The main methods are patient referral, provider referral, contract referral, and outreach assistance. Contract referral, also known as conditional referral, is when index patients are encouraged to inform their partners, on the understanding that health service personnel will notify those partners who do not visit the health service within a contracted time period. Provider referral is when third parties (usually health service personnel) notify partners identified by index patients without disclosing the name of the patient to the partners. Patient referral is usually facilitated by use of contact cards that are given by the clinician to the index patient to pass on to his or her partner(s). Contact cards may contain the details of the index patient's diagnosis. In outreach assistance, partners are notified by members of an outreach team indigenous to the community, who do not disclose the name of the patient to the partners. ${ }^{5}$

The stigma attached to STIs makes partner notification difficult. Patient referral is usually preferred by patients and doctors for most curable STIs. ${ }^{6}$ For HIV infection, the patient referral approach is also the preferred one in developing countries, as per some review studies. This approach is also in accordance with the World Health Organization recommendation that patient-based notification be the first step in developing countries. ${ }^{7}$ Counseling for index STI patients on partner notification has been found to be effective for increasing partner referrals in studies conducted in Zambia, Zimbabwe, and Kenya. However, the major challenge facing this intervention is that counselors are not available in health centers in most developing countries. ${ }^{8}$

Some studies support a different approach, such as the combination of contact tracing and screening for chronic viral diseases, including HIV infection. According to the model of such interventions, first, the optimal strategy is to get infected individuals into treatment as fast as possible when the disease prevalence is above the cost-effective equilibrium. Second, as one reduces the disease prevalence by moving people into treatment (which decreases the chance that they will infect others), one should increase the level of contact tracing to compensate for the decreased effectiveness of screening. ${ }^{9}$ This strategy, also referred to as the "partner notification program", is believed to be one of the major reasons for the low HIV prevalence rate in Cuba compared with its neighbors in the Caribbean region. One of the relevant studies recommends that increasing the efficiency of contact tracing (higher contact tracing rates) is ideal for large-scale intervention programs in developing countries with limited resources. ${ }^{10}$

Concurrency (partnerships in which the dates of first and last sexual contact overlap) is a common situation which has to be addressed as part of partner notification and referral. In a study conducted in Uganda, the concurrency rate among those reporting a sexual partner in the past year was found to be $17 \%$ in men and $0.5 \%$ in women. The same study showed that the reported condom use was very low, with $91 \%$ of men reporting not using a condom during the last sexual encounter with their partners. ${ }^{11}$ A study conducted in the US among low-income women showed that those who engaged in high-risk behaviors with their sexual partners tended not to use condoms. About half of the women believed their partners had partners at the same time as they were partners with them (partner concurrency). ${ }^{12}$ Such relationships need strong partner referral strategies after HIV testing.

In a systematic review of the willingness of clients regarding partner notification and referral, little correlation was found between the willingness of patients to notify their partners and their reported success. In one study, $86 \%$ of patients were willing to notify their partners, but only $30 \%$ of partners were reported as notified. ${ }^{8}$ Findings from sub-Saharan Africa show that the majority of HIVpositive individuals first disclose their status to a close family member before disclosing it to a partner or spouse. Even in studies showing high rates of reported disclosure to partners, there is a relatively low uptake of partner HIV testing, which highlights an area for intervention. ${ }^{13}$ Clients report several major barriers to notifying partners, including embarrassment, fear of rejection, the stigma associated with the disease, and difficulty in locating casual partners. ${ }^{8}$

Routine HIV counseling and testing is recommended as an integral component of expansion of HIV prevention, care, and treatment services in Africa and other areas where the prevalence of HIV is high. ${ }^{14}$ However, emphasis on a plausible partner referral strategy for widespread positive case detection has to be well thought out and developed. The major objective of this study is to identify approaches that 
improve acceptance of partner referral after an HIV-positive test result. The study reduces the paucity of knowledge about partner referral strategies by investigating the views of health care service providers and HIV-positive clients on partner notification and subsequent uptake of partner referral for HIV testing.

\section{Materials and methods}

The purpose of this research was to develop a strategy for promoting the concept that "an active, integrated and comprehensive HIV-positive client's partner notification and referral approach is more effective than the current widely used passive and single strategic approach". A qualitative study using indepth interview methodology was undertaken among newly tested HIV-positive clients to identify partners needing notification and acceptance of referral by their partners in Addis Ababa, Ethiopia, between July and August 2012. The study was conducted in two private nonprofit voluntary counseling and testing centers. Saturation was reached after interviewing 15 newly tested HIV-positive clients.

At the end of the post-test counseling and interview, referral cards were provided to all clients and they were encouraged to give these to their partners, with further disclosure to be made by themselves or their counselors. These newly HIV-positive clients were followed for one month to assess whether their partners were provided with the referral cards, referred, and tested for HIV. Eleven health care service providers working in the HIV testing and counseling units of seven large private clinics and four medium-sized clinics in Addis Ababa were also provided with open-ended structured questionnaires in order to assess their views toward partner notification strategies for newly tested HIV-positive clients. Data from both sources were manually transcribed and categorized. Seven themes were developed, with two additional themes added (challenge of partner notification/ referral and counselor's recommendation). Informed consent was obtained from all participants in the study. The semistructured questionnaires used in this study are shown in Figures 1 and 2.

\section{Results}

Indepth interviews were conducted with 15 newly tested HIV-positive clients, of mean age 32 years. Three quarters of the participants were female, half were single, and the rest were married or divorced. Most were Orthodox Christian. The mean number of years spent living together with their partners was 5.7 years. Eight had had multiple sexual partners. Three participants were in concurrent relationships at the time of interview. All participants learned of their HIV test result during the study period and were given referral cards by HIV counselors to provide to their partners.

A total of 11 counselors working in 11 private large-sized or medium-sized clinics providing voluntary counseling and testing services completed the self-administered, structured questionnaire. The mean age of the counselors was 26 years, and the majority were women. All were working in profitmaking or nonprofit-making private health care facilities located in Addis Ababa. All were registered nurses and eligible to take up a position as an HIV counselor after 2-3 weeks training on HIV counseling and testing. Trained HIV/AIDS counselors were selected because studies have shown that counselors who have attended counseling training are about

1. Age ____________ Gender __________ Marital status

2. How many years have you been married or living together with your partner/s?

3. Is this the first time you have been told your serostatus is positive? How many partners have you had and how long have you lived as concurrent partner(s)?

4. Have you discussed testing with your partner(s) before? Why?

5. Do you know the HIV status of your partner(s)? If so, what is it?

6. Will you notify your result to your partner(s)? How?

7. How long would you want to wait before you disclose your positive result to your partner(s)?

8. Do you think disclosure of your HIV status is important to your partner(s) or family? Why?

9. To whom will you disclose your HIV infection first? Your partner? Family members? Other?

10. What will be the major challenge to disclosing your HIV status to your partner(s)?

11. What method of status notification do you prefer? Disclosure by yourself? Disclosure by a counselor or another third person? Why?

12. If you disclose your result, what will be the major challenges you expect to encounter from your partner and family members? Why?

13. Do you think it is preferable to provide a referral slip to clients testing HIV-positive and that disclosure be done by a service provider rather than by HIV-positive clients themselves? Why?

14. Are you willing to accept and deliver the referral slip we are going to give you to your partner(s)? 
Position ....................................

Type of health facility

Qualification

2. How long you have worked in HIV counseling and testing?

3. How many of the clients you tested in the last three months are HIV-positive?

4. What kind of partner referral method are you using (verbal communication of clients to partner, a referral slip, or other?)

perther a referalsip. or other?)

How many of your HIV-positive clients' partners come to clinic after partner notification counseling is given?

6. What do you think are the challenges linked to the current passive and verbal HIV partner notification approach?

(n)

7. What are the reasons for clients testing HIV-positive not notifying their partners about their HIV-positive test result?

8. Do you think providing partners with written referral slips in clinic improves the HIV testing rate of partners? Why?

9. Do you think disclosing a client's HIV-positive test result to partners is better done by health service providers directly than by notification through the HIV-positive clients? Why?

10. Do you agree that if HIV-positive clients give the telephone and contact address of their partner(s) that "contact tracing" should be made by service providers for HIV counseling and testing? Why?

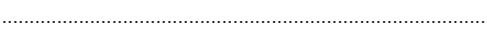

……

11. Do you think a home visit to HIV-positive clients by an outreach/community health worker would improve the rate of disclosure and testing of partners? Why?

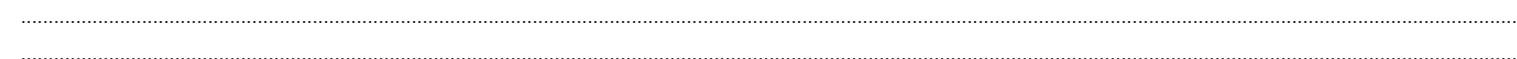

12. What effective method do you think could improve partner notification and referral after HIV-positive testing?

(n)

Thank you for participating in the study

Figure 2 Semistructured questionnaire for service providers on partner notification after HIV-positive test.

10 times more likely than untrained providers to discuss partner notification. ${ }^{15}$ The mean number of years of work experience as an HIV counselor was 2 years. The counselors had counseled an average of $75 \mathrm{HIV}$-positive clients during their career.

\section{Preference for disclosure}

In this study, seven of the 11 counselors preferred to disclose the HIV test result to their patients' partners, and others preferred to disclose the result to close relatives. Thirteen of the 15 newly diagnosed HIV-positive patients preferred that disclosure of their positive result be done through an HIV counselor rather than by themselves. Ten of the 11 HIV counselors, who provided HIV counseling and testing at clinics, also suggested that the HIV test result be disclosed through service providers rather than client notification to partners. Ten of the 11 counselors agreed in reaching HIV-positive clients' partners through outreach and home visits to improve the disclosure process and referral for HIV testing. 


\section{Knowledge about importance of partner referral}

Twelve of the 15 newly diagnosed HIV-positive participants believed that it was important to disclose their HIV test result to their partners for the sake of their family. They pointed out that unless they disclosed their positive result to partners, they would risk transmission of the disease within their family, eg, by sharing sharp objects. A 28-year-old HIV-positive male participant said "Unless my partner knows the status of my blood, the disease transmission continues and controlling the disease in the family level itself will be difficult".

\section{Pretest discussion with partner}

Ten of the 15 newly tested HIV-positive participants did not know the HIV status of their partners at the time that they tested positive themselves. Of these, eight had had no discussion with their partners before being tested for HIV, for fear that their partners might request disclosure of the result. Five newly diagnosed HIV-positive clients had known their partners' HIV status before they were tested. Three reported the HIV status of their partners to be positive, and two reported it to be negative. The reasons commonly mentioned by HIV-positive clients for not discussing their decision to be tested for HIV with their partners in advance of the test were the fear of receiving a positive result and the expectation of disharmony thereafter. A 30-year-old newly diagnosed HIV-positive woman participant said "I did not inform my husband when I came for the HIV test because I expected he would disagree with me about having the test".

\section{Desire for partner notification}

Eleven of our 15 clients who tested HIV-positive did not wish to disclose their HIV test result to their partners immediately. A 29-year-old married woman mentioned "I will not disclose my HIV test result because I know it will create endless conflict with my husband, and I prefer to wait until my health deteriorates and then he knows it". Some participants mentioned that the reason for not disclosing their positive result immediately to their partners was because they feared that the positive result lead to accusations of infidelity.

\section{Acceptance of referral card by clients testing HIV-positive}

All 15 HIV-positive clients agreed with provision of the referral card. The information contained in the referral card includes the name and contact address of the clinic and the name of the counselor who sent the card, indicating that it was sent for the purpose of discussing health-related issues which would benefit the partner and their family. The referral card did not include the diagnosis of HIV in their partner. The referral card allowed a one-month time line for the partner to attend the clinic and included the contact address for a health professional so that the partner could make contact by telephone if necessary. Eight of the 15 study participants were willing to provide the referral document to their partners, so that the disclosure could be done by service providers rather than by themselves. This is because they believed that counselors know more about HIV and can provide the correct information to their partners. Seven participants, although they took the referral card, preferred that the disclosure be done by themselves when it became necessary, so their confidentiality and the right to disclose the result themselves was maintained. Partners of five of the eight HIV-positive clients actually came to the clinic for counseling and testing (all not previously testing positive).

Provision of referral cards to newly diagnosed HIV-positive clients so that disclosure could be done with involvement of the counselor was investigated from the perspective of the counselor. Five of the 11 counselors agreed strongly that provision of written referral cards for subsequent provider involvement could improve the partner notification and referral process, as well as the HIV counseling and testing rate for partners. The majority of counselors agreed that provision of referral cards to clients testing positive for HIV encourages partners to accept HIV testing by increasing their responsiveness to what patients explained and the counselors requested. A 28-year-old counselor stated that "referral cards serve as a clue for partners to realize that they are at risk, and they are then encouraged to come and receive professional counseling and get notified about their partner's HIV-positive status. This might in turn influence their decision to take an HIV test themselves".

\section{Acceptance of referral by HIV-positive partners}

Of the 15 newly tested HIV-positive clients who were provided with referral forms to give to their partners, eight confirmed that they had done so. Five partners of these eight clients who passed on the referral card visited the health facilities, and notification was done by the counselors. All partners referred had not previously tested positive for HIV, and accepted testing on the same day. Three of them tested HIV-positive and two tested HIV-negative.

\section{Information on partner location}

Nine of the 11 counselors did not agree with the approach of HIV-positive clients providing partner addresses for 
contractual referral and contact tracing purposes. They repeatedly pointed out that it would be a breach of client confidentiality and the client's right to withhold information about their HIV status.

\section{Challenges to partner notification and referral}

Eight of the 11 HIV counselors reported challenges when using verbal communication for partner referral. Stigma and discrimination were repeatedly mentioned by HIV-positive clients during the study interview. The counselors commented that most clients would be reluctant to tell a partner about their HIV-positive test result out of fear of their partner's reaction to such a disclosure. It was also mentioned that HIV-positive clients may not understand the message correctly and lack the necessary disclosure skills due to the brief post-test counseling session with the HIV counselor. Further, conservative cultural and societal norms often prevent full disclosure to partners (people prefer to keep their HIV test result secret rather than openly discussing the issue). The counselors also pointed out that some clients miss important messages given during the post-test counseling session, often being emotionally distraught after learning of their positive test result.

The counselors noted another challenge associated with the referral card provision and disclosure system, ie, it may create conflict between partners, and confidentiality may easily be broken, especially for clients or partners who are unable to read and write. For HIV-positive clients, fear of separation was the main reason given by the counselors for clients not wanting to disclose a positive result and arrange partner referral. A female HIV counselor with four years of experience in HIV counseling said "If one of the partners is positive, mainly the husband, it is common for the relationship to end either in separation or divorce". The commonly mentioned challenges facing newly tested HIV-positive clients pertaining to disclosure of their HIV status to partners were the following: lack of channels for open discussion with the partner; apprehension about possible divorce; fear of stigma and discrimination by family and community; and fear about accusations of infidelity.

\section{Recommendation by HIV counselors}

Most counselors recommended that there should be easy access to HIV testing and counseling to avoid physical and finance-related barriers. They also stressed the importance of intensive post-test counseling for HIV-positive clients in order to prepare them for partner notification and referral. The majority of counselors agreed on the need for a comprehensive and client-contextualized partner notification and referral strategy. This strategy includes active involvement of counselors in encouraging HIV-positive clients on disclosure, providing referral forms, communicating with tested clients through their contacts, assisting clients in disclosing HIV-positive results, and linking the HIV counseling and testing service with outreach partner notification and referral assistance. The result are summarized for each theme in Table 1.

\section{Discussion}

Early disclosure of an HIV-positive result to one's partner(s) is very important for prevention of disease transmission and early treatment. In our study, seven of 15 newly diagnosed HIV-positive clients preferred to disclose the HIV test result to their partners, whereas others preferred to disclose their results only to their close relatives. Some of the factors influencing to whom a positive HIV test result is communicated include the client's ability to cope with a positive result, concern about conflict among family members, and fear of stigmatization and discrimination. Persons who live with HIV infection for some time may feel that they know how to disclose their HIV status and often gain experience in disclosing this to other people. ${ }^{16}$ However, it is critical to encourage and support clients who prefer to disclose their HIV result only to close relatives to notify their partners early, because delayed partner notification can increase the risk of new HIV infection and opportunities lost with regards to prevention and treatment.

The HIV counselors mentioned that information and counseling structured by health professionals is far better than passive patient notification, which may result in misunderstandings and conflict. Ten of 11 counselors agreed about contact being made with HIV-positive clients' partners through outreach services and home visits to improve disclosure and referrals for HIV testing. This finding is consistent with that of a study which compared the effectiveness of different strategies for partner counseling and a referral service which indicated that the dual referral method (whereby index clients notify their partners with a disease intervention specialist or provider present) is the most effective method. ${ }^{16}$ It is recommended that such active organizational and provider-level interventions for partner notification are needed to realize the cost-effectiveness benefits of expanded HIV testing and counseling. ${ }^{15}$ Our findings from both newly diagnosed HIV-positive clients and HIV counselors support the patient referral and outreach assistance partner notification approach and referral methods for disclosure, preferably done by HIV counselors.

The majority of participants did not know the HIV status of their partners at the time they tested positive, and most 
Table I Theme results and comments from a qualitative study conducted on HIV referral acceptance by partners of clients testing HIV-positive, Addis Ababa, Ethiopia, 2012

\begin{tabular}{|c|c|c|}
\hline Theme & Findings & Comments \\
\hline $\begin{array}{l}\text { I. Disclosure preference } \\
\text { of HIV-positive clients. }\end{array}$ & $\begin{array}{l}\text { Seven preferred to notify their partner(s) directly, while } \\
\text { five preferred to disclose through close relatives rather } \\
\text { than themselves. Four clients could not tell either. }\end{array}$ & $\begin{array}{l}\text { Clients who prefer to disclose HIV-positive results } \\
\text { to close relatives need to be encouraged and } \\
\text { supported to disclose results to their partners. }\end{array}$ \\
\hline $\begin{array}{l}\text { 2. HIV-positive clients' knowledge } \\
\text { about partner notification } \\
\text { and referral. }\end{array}$ & $\begin{array}{l}\text { Twelve clients knew the importance of partner } \\
\text { notification and referral. }\end{array}$ & $\begin{array}{l}\text { Knowledge of clients testing positive about } \\
\text { partner notification and referral may not } \\
\text { necessarily be linked with the actual practices } \\
\text { which help partners to be referred and tested. }\end{array}$ \\
\hline $\begin{array}{l}\text { 3. HIV-positive clients' pretest } \\
\text { discussion with partners. }\end{array}$ & $\begin{array}{l}\text { Ten newly positively tested clients did not know } \\
\text { the HIV status of their partners, and eight did not } \\
\text { discuss with their partners that they planned to } \\
\text { have an HIV test. }\end{array}$ & $\begin{array}{l}\text { Failure to have a pretest discussion with } \\
\text { partner(s) about having an HIV test may } \\
\text { encourage clients to hold back an HIV-positive } \\
\text { result from their partners. }\end{array}$ \\
\hline $\begin{array}{l}\text { 4. HIV-positive clients' desire } \\
\text { for partner notification. }\end{array}$ & $\begin{array}{l}\text { Twelve participants did not want to disclose } \\
\text { their positive status immediately. }\end{array}$ & $\begin{array}{l}\text { Fear of separation and bearing the burden of } \\
\text { infidelity is a common reason for not wanting } \\
\text { immediate disclosure. }\end{array}$ \\
\hline $\begin{array}{l}\text { 5. Referral card acceptance by clients } \\
\text { testing positive. }\end{array}$ & $\begin{array}{l}\text { All clients testing positive agreed and took the } \\
\text { referral card, but only eight were willing } \\
\text { to provide the card to their partners. }\end{array}$ & $\begin{array}{l}\text { Willingness to accept a referral card from } \\
\text { counselors does not necessarily mean that HIV- } \\
\text { positive clients are willing to provide the cards to } \\
\text { their partners. This is the time when contractual } \\
\text { referral and outreach assistance might be essential. }\end{array}$ \\
\hline $\begin{array}{l}\text { 6. Referral acceptance by partners } \\
\text { of HIV-positive clients. }\end{array}$ & $\begin{array}{l}\text { Five of eight partners of clients testing positive } \\
\text { who were provided with referral cards accepted } \\
\text { referral and tested for HIV. }\end{array}$ & $\begin{array}{l}\text { There is a high HIV test rate among partners } \\
\text { who accept referral cards. }\end{array}$ \\
\hline 7. Getting partner locator information. & $\begin{array}{l}\text { Nine of I I counselors did not agree about seeking } \\
\text { partner locator information from HIV-positive clients } \\
\text { for contractual referral and/or outreach assistance. }\end{array}$ & $\begin{array}{l}\text { HIV counselors do not fully comprehend the } \\
\text { recommendations made by the International } \\
\text { Guidelines on HIVIAIDS and Human Rights for } \\
\text { service providers on making the decision to } \\
\text { inform partners of patients testing HIV-positive. }\end{array}$ \\
\hline $\begin{array}{l}\text { 8. Challenges to HIV-positive clients } \\
\text { concerning partner notification } \\
\text { and referral. }\end{array}$ & $\begin{array}{l}\text { Fear of separation and divorce, stigma and discrimination, } \\
\text { financial dependence on partners, and fear of the burden } \\
\text { of infidelity in the relationship were mentioned } \\
\text { as barriers to partner notification and referral. }\end{array}$ & $\begin{array}{l}\text { HIV counselors need to identify specific } \\
\text { challenges to HIV-positive clients and actively } \\
\text { assist in the partner notification and disclosure } \\
\text { process. }\end{array}$ \\
\hline $\begin{array}{l}\text { 9. Recommendation by HIV counselors } \\
\text { to improve HIV-positive partner } \\
\text { notification and referral. }\end{array}$ & $\begin{array}{l}\text { Improving access to HIV counseling and testing, providing } \\
\text { thorough post-test counseling, and customizing partner } \\
\text { notification based on clients' context. }\end{array}$ & $\begin{array}{l}\text { A comprehensive and client-contextualized } \\
\text { partner notification and referral strategy has to } \\
\text { be implemented. }\end{array}$ \\
\hline
\end{tabular}

had had no discussion with their partners before HIV testing for fear of their partners request for disclosure of the result. The reason commonly mentioned by HIV-positive clients for not discussing their decision to be tested for HIV was the fear of receiving a positive result and the expectation of disharmony thereafter. Partner notification and disclosure of a positive result is particularly challenging for women who live in a male-dominated society. In such communities, where large numbers of patients testing HIV-positive do not know the HIV status of their partners and who cannot discuss HIV testing with them, counselor-assisted partner notification can be particularly important. This notion is consistent with the finding that "provider-assisted partner notification is an important method to increase testing among male partners". ${ }^{17}$
Our 15 HIV-positive clients agreed with provision of a referral card. The brief information contained in the referral card is very important for partner referral and easy communication between HIV-positive patients and their partners. The fact that the referral card does not include a diagnosis facilitates the disclosure being done by professional counselors. The referral card establishes a one-month time line for partners to present to the clinic and contains the contact address for a health professional so that the partners can make contact by telephone if necessary, and refer the case to outreach assistance if the partner is at risk of infection. The partners of five of the eight HIV-positive clients actually agreed and came to the clinic for counseling and testing, representing one third (five of 15) of the HIVpositive clients to whom a referral card was provided and 
three fifths (five of eight) of those who actually provided referral cards to their partners.

This finding is consistent with another report showing substantial differences in the rates of partner notification discussions compared to the actual agreement for HIV testing. While partner discussion is relatively common (about two-thirds of test cases), rates of agreement about partner notification with involvement of a health care provider are much lower, ie, about $10 \%$ of total positive test cases reported. Positive test cases involving clients who did not visit the organization to request an HIV test and who also did not present with symptoms or exposure risk were less likely to have partner notification discussion. Given the pressures limiting the amount of time a provider can spend with each patient, and the multiple competing priorities inherent in post-test counseling, this makes sense in terms of risk of transmission. ${ }^{15}$

Provision of a referral card to the positively tested client so that disclosure can be done with a counselor's involvement was investigated from the counselor's perspective. Five of the 11 counselors strongly agreed that provision of a written referral card for subsequent provider involvement could improve partner notification and referral as well as HIV counseling and testing rates. A study conducted in the US has shown that the passive model is ineffective for identifying partners with unrecognized HIV infection. ${ }^{18}$ Another study conducted in Malawi showed that such provider-assisted partner notification was effective in patients attending STI clinics. The study found that provider-assisted methods of HIV partner notification were feasible, acceptable, and effective among STI clinic patients. A high proportion of eligible patients participated and provided accurate partner locator information. Provider-assisted partner notification was implemented without difficulty and was supported by clinic staff. Provider-assisted partner notification resulted in more partners receiving counseling and testing services than passive referral, which is the current standard of care. ${ }^{17}$

The five referred HIV-positive partners had not been tested previously and accepted HIV testing on the same day, of which three tested HIV-positive and two were HIVnegative. This finding suggests a high rate of acceptance of the referral card and HIV testing among partners of HIV-positive clients using the client referral approach with disclosure made by counselors, as compared with traditional verbal communication done by HIV-positive clients. In a study conducted in Bangladesh among 1339 STI clients, $81 \%$ accepted partner referral cards but only $32 \%$ actually referred their partners. ${ }^{19}$ Active involvement of HIV counselors in encouraging and supporting clients testing HIV-positive in the partner notification and referral process results in early disclosure of test results and HIV testing of the partners. The finding is consistent with a quantitative study showing that 779 (29\%) of 2678 index clients provided partner locator information. A total of 1048 partners were identified, of whom 463 (44\%) were both interviewed and tested for HIV. Thirty-seven partners (8\%) were newly diagnosed with HIV. The partner counseling and referral service provides testing and prevention services for people at high risk of HIV infection. ${ }^{18}$ A study conducted in Bangladesh showed that partner referral intention was best predicted by the attitudes and perceived social norms of clients. Actual partner referral was significantly associated with intention to refer the partner and the attitudes of the index clients. Married clients were significantly more likely to refer their partners, and clients with a low income were least likely to refer partners. Intervention programs must address psychosocial and socioeconomic issues to improve partner disclosure. ${ }^{19}$

Successful partner notification is contingent on index patients providing locator information for their partners, and community counselors successfully locating those partners. ${ }^{17}$ However, most counselors did not agree with the approach of HIV-positive clients providing addresses for their partners for contractual referral and contact tracing purposes. They repeatedly pointed out that this would be a breach of client confidentiality and the right of their clients to privacy concerning their HIV status. This indicates that the counselors themselves do not understand the recommendation on international human rights in relation to HIV/ AIDS. The important conditions included in the International Guidelines on HIV/AIDS and Human Rights for service providers to decide and inform their patients' HIV status to their patients' partners are when the HIV-positive person has refused to notify or consent to the notification of his/ her partner(s) and when a real risk of HIV transmission to the partner(s) exists. ${ }^{20}$ For such active intervention through contract referral and outreach assistance, information from HIV-positive clients on partner location is very important. In fact, obtaining accurate and reliable information on partner location from clients who test positive is easier said than done. In a study conducted in the US, index clients who were older than 25 years of age, male, or reported having male-male sex in the past 12 months were more likely to refuse to provide partner information. The proportion of partners who were located and offered partner counseling and referral services differed according to the referral 
approach used, ranging from $38 \%$ using contract referral (index clients agree to notify their partners within a certain time frame, or else a disease intervention specialist or health care provider will notify them) to $98 \%$ using the dual referral method (index clients notify their partners with a disease intervention specialist or provider present). ${ }^{16}$

The decision of health care professionals to disclose an HIV-positive status to the clients' partners should be conducted in a well balanced and efficient way. This needs to be done in line with the public health legislation which authorizes, but does not require, that health care professionals decide, on the basis of each individual case and ethical considerations, whether to inform a patient's sexual partner(s) of the HIV status of their patient. Such a decision should only be made in accordance with the following criteria: the HIV-positive person in question has been thoroughly counseled; counseling of the HIV-positive person has failed to achieve appropriate behavioral changes; the HIV-positive person has refused to notify or consent to the notification of his/her partner(s); a real risk of HIV transmission to the partner(s) exists; the HIV-positive person is given reasonable advance notice; the identity of the HIV-positive person is concealed from the partner(s), if this is possible in practice; and follow-up is provided to ensure support to those involved, as necessary. ${ }^{20}$ It is thus imperative for HIV counselors to know and balance the right of the client to privacy and confidentiality versus the client's partner's right to be protected from infection as stated in universally recognized human rights in relation to HIV infection.

From this study, it can be concluded that it is very important to provide a comprehensive and integrated partner notification service in which HIV counselors play an active role based on a comprehensive and integrated partner notification and referral framework (see Figure 3). Clients testing HIVpositive who agree to notify their partners should be given a referral form and monitored. If they notify and/or refer their partners, the partners would receive notification and/or HIV counseling and testing. If they have agreed upon notification and referral but have failed to do so, partner notification will be done through an outreach assistance approach. If HIVpositive clients refuse to accept both partner referral and the provision of referral cards to their partners, clients will be provided with a contractual time frame and full disclosure will be done through outreach assistance. Clients' partners who are tested and found to be positive need to be encouraged to disclose their positive results to their partner(s) so that they can further participate in the subsequent partner notification and referral process.

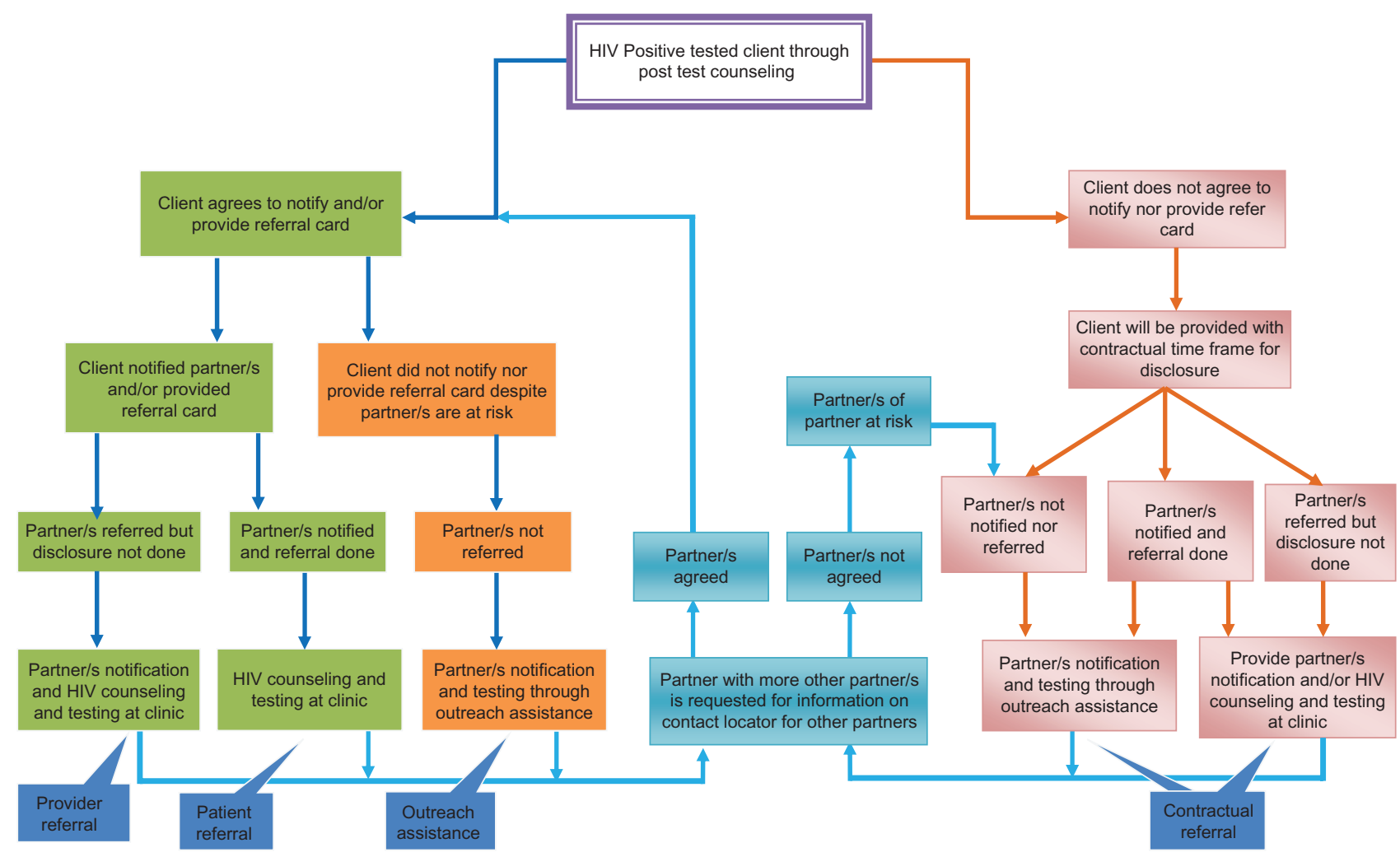

Figure 3 Conceptual framework for comprehensive, integrated and active involvement of HIV counselors in partner notification and referral. 


\section{Conclusion}

Partner notification and referral can be improved through integrated, comprehensive active involvement of HIV counselors in the disclosure process. Active involvement of counselors with regards to partner notification and referral includes encouraging HIV-positive clients to disclose their serostatus, providing referral cards to HIV-positive tested clients, communicating with HIV-positive clients through their contacts for notification status, contacting the clients' partners (when necessary), assisting clients with disclosure of their HIV-positive status, and linking the HIV counseling and testing service with outreach partner notification and referral assistance.

\section{Disclosure}

The authors report no conflicts of interest in this work.

\section{References}

1. Hogben M, McNally T, McPheeters M, Hutchinson AB. The effectiveness of HIV partner counseling and referral services in increasing identification of HIV-positive individuals - a systematic review. Am J Prev Med. 2007;33(Suppl 2):S89-S100.

2. Abaynew Y, Deribew A, Deribe K. Factors associated with late presentation to HIV/AIDS care in South Wollo Zone Ethiopia: a casecontrol study. AIDS Res Ther. 2011;8:8.

3. Eustace RW, Ilagan PR. HIV disclosure among HIV-positive individuals: a concept analysis. J Adv Nurs. 2010;66:2094-2103.

4. Njozing BN, Edin KE, Sebastián MS, Hurtig AK. If the patients decide not to tell what can we do? - TB/HIV counselors' dilemma on partner notification for HIV. BMC Int Health Hum Rights. 2011;11:6.

5. Mathews C, Coetzee N. Partner notification. Clin Evid (Online). 2009;2009:pii1605.

6. Trelle S, Shang A, Nartey L, Cassell JA, Low N. Improved effectiveness of partner notification for patients with sexually transmitted infections: systematic review. BMJ. 2007;334:354

7. World Health Organization and Joint United Nations Programme on HIV/AIDS. Sexually Transmitted Diseases: Policies and Principles for Prevention and Care. Geneva, Switzerland: UNAIDS Best Practice Collection; 1999.
8. Alam N, Chamot E, Vermund SH, Streatfield K, Kristensen S. Partner notification for sexually transmitted infections in developing countries: a systematic review. BMC Public Health. 2010;10:19.

9. Armbruster B, Brandeau ML. Cost-effective control of chronic viral diseases: finding the optimal level of screening and contact tracing. Math Biosci. 2010;224:35-42.

10. Hsieh YH, Wang YS, de Arazoza H, Lounes R. Modeling secondary level of HIV contact tracing: its impact on HIV intervention in Cuba. BMC Infect Dis. 2010;10:194.

11. Maher D, Waswa L, Karabarinde A, Baisley K. Concurrent sexual partnerships and associated factors: a cross-sectional population-based survey in a rural community in Africa with a generalized HIV epidemic. BMC Public Health. 2011;11:651.

12. Ober AJ, Iguchi MY, Weiss RE, et al. The relative role of perceived partner risks in promoting condom use in a three-city sample of highrisk, low-income women. AIDS Behav. 2011;15:1347-1358.

13. Kiene SM, Bateganya M, Wanyenze R, Lule H, Nantaba H, Stein MD. Initial outcomes of provider-initiated routine HIV testing and counseling during outpatient care at a rural Ugandan hospital: risky sexual behavior, partner HIV testing, disclosure, and HIV care seeking. AIDS Patient Care STDS. 2010;24:117-126.

14. Wanyenze RK, Nawavvu C, Namale AS, et al. Acceptability of routine HIV counselling and testing, and HIV seroprevalence in Ugandan hospitals. Bull World Health Organ. 2008;86:302-309.

15. Swendeman DT, Grusky O, Swanson AN. HIV partner notification: predictors of discussion and agreements from provider reports. AIDS Behav. 2009; 13:573-581.

16. Song B, Begley EB, Lesondak L, et al. Partner referral by HIV-infected persons to partner counseling and referral services (PCRS) - results from a demonstration project. Open AIDS J. 2012;6:8-15.

17. Brown LB, Miller WC, Kamanga G, et al. HIV partner notification is effective and feasible in Sub-Saharan Africa: opportunities for HIV treatment and prevention. J Acquir Immune Defic Syndr. 2011;56: $437-442$.

18. Begley EB, Oster AM, Song B, et al. Incorporating rapid HIV testing into partner counseling and referral services. Public Health Rep. 2008; 123 Suppl 3:126-135.

19. Alam N, Streatfield PK, Khan SI, Momtaz D, Kristensen S, Vermund SH. Factors associated with partner referral among patients with sexually transmitted infections in Bangladesh. Soc Sci Med. 2010;71:1921-1926.

20. International Guidelines on HIV/AIDS and Human Rights 2006 consolidated version. Joint United Nations Program on HIV/AIDS; 2006. Available from: http://data.unaids.org/Publications/IRC-pub07/ jc1252-internguidelines_en.pdf. Accessed November 18, 2012.
HIV/AIDS - Research and Palliative Care

\section{Publish your work in this journal}

HIV/AIDS - Research and Palliative Care is an international, peerreviewed open-access journal focusing on advances in research in HIV, its clinical progression and management options including antiviral treatment, palliative care and public healthcare policies to control viral spread. The journal welcomes original research, basic science,

\section{Dovepress}

clinical \& epidemiological studies, reviews \& evaluations, expert opinion \& commentary, case reports \& extended reports. The manuscript management system is completely online and includes a very quick and fair peer-review system. Visit http://www.dovepress.com/ testimonials.php to read real quotes from published authors. 